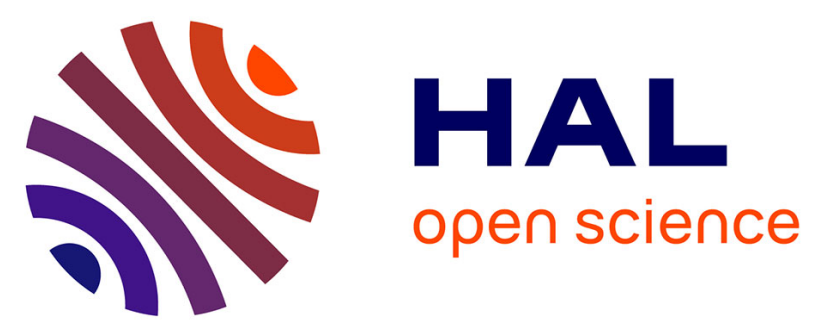

\title{
Long-Chain Branched Polyethylene via Coordinative Tandem Insertion and Chain-Transfer Polymerization Using rac-EBTHIZrCl2/MAO/Al-alkenyl Combinations: An Experimental and Theoretical Study
}

M. Santoro, Lorenzo Piola, Karl Mc Cabe, Olivier Lhost, Katty den Dauw, Aurélien Vantomme, Alexandre Welle, Laurent Maron, Jean-François Carpentier, Evgueni Kirillov

\section{- To cite this version:}

M. Santoro, Lorenzo Piola, Karl Mc Cabe, Olivier Lhost, Katty den Dauw, et al.. Long-Chain Branched Polyethylene via Coordinative Tandem Insertion and Chain-Transfer Polymerization Using rac-EBTHIZrCl2/MAO/Al-alkenyl Combinations: An Experimental and Theoretical Study. Macromolecules, 2020, 53 (20), pp.8847-8857. 10.1021/acs.macromol.0c01671 . hal-03040883

\section{HAL Id: hal-03040883 https://hal.science/hal-03040883}

Submitted on 10 Dec 2020

HAL is a multi-disciplinary open access archive for the deposit and dissemination of scientific research documents, whether they are published or not. The documents may come from teaching and research institutions in France or abroad, or from public or private research centers.
L'archive ouverte pluridisciplinaire HAL, est destinée au dépôt et à la diffusion de documents scientifiques de niveau recherche, publiés ou non, émanant des établissements d'enseignement et de recherche français ou étrangers, des laboratoires publics ou privés. 


\section{Long-Chain Branched Polyethylene via Coordinative Tandem Insertion and Chain-Transfer Polymerization Using rac-\{EBTHI $\} \mathrm{ZrCl}_{2} / \mathrm{MAO} / \mathrm{Al}$-alkenyl Combinations:}

\section{An Experimental and Theoretical Study}

Orlando Santoro, ${ }^{\mathrm{a}, \dagger}$ Lorenzo Piola,${ }^{\mathrm{a}, \dagger}$ Karl Mc Cabe,,${ }^{\mathrm{c}}$ Olivier Lhost, ${ }^{\mathrm{b}}$ Katty Den Dauw, ${ }^{\mathrm{b}}$ Aurélien Vantomme, ${ }^{\mathrm{b}}$ Alexandre Welle, ${ }^{\mathrm{b}}$ Laurent Maron, ${ }^{\mathrm{c},{ }^{*}}$ Jean-François Carpentier ${ }^{\mathrm{a},{ }^{*}}$ and Evgueni Kirillov, ${ }^{\mathrm{a},}$

a Univ Rennes, CNRS, Institut des Sciences Chimiques de Rennes (ISCR), UMR 6226, F35042 Rennes, France

b Total Research \& Technology Feluy, Zone Industrielle Feluy C, B-7181 Seneffe, Belgium c Université de Toulouse, CNRS, INSA, UPS, LPCNO, UMR 5215, 135 avenue de Rangueil, F-31077 Toulouse Cedex 4, France

\section{Graphical Abstract / For the Table of content entry}

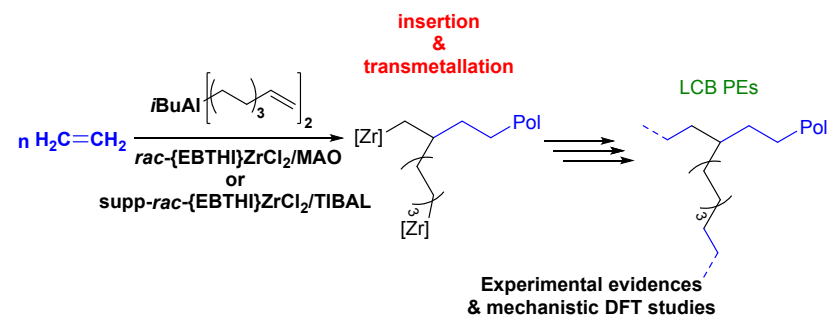

$\uparrow$ Those two authors equally contributed to this work.

* Correspondence to Laurent Maron (laurent.maron@,irsamc.ups-tlse.fr), Jean-François Carpentier (jean-francois.carpentier@univ-rennes1.fr) and Evgueni Kirillov (evgueni.kirillov@univ-rennes1.fr). 


\begin{abstract}
In situ synthesis of topologically modified linear polyethylenes using single-site polymerization catalysis is a challenging task but it can enable the production of valuable advanced polymer materials with tailored properties. Described herein is an investigation aimed at the efficient generation of long-chain branches (LCB) in linear polyethylenes using Al-alkenyl species, namely $i \mathrm{BuAl}($ oct-7-en-1-yl) 2 (Al-1), in combination with homogeneous rac- $\{\mathrm{EBTHI}\} \mathrm{ZrCl}_{2} / \mathrm{MAO}$ or heterogeneous $\mathrm{MAO}$ on silica-supported-rac$\{$ EBTHI $\} \mathrm{ZrCl}_{2} / \mathrm{TIBAL}$ catalytic systems. As corroborated by extensive rheological studies and ${ }^{13} \mathrm{C}$ NMR spectroscopy, the Al-alkenyl reagent was found quite efficient in the formation of LCB, via a mechanistic pathway involving both insertion and transmetallation reactions. Formation of LCB has been rationalized by DFT computations carried out on the putative $[\text { rac- }\{\mathrm{EBTHI}\} \mathrm{Zr}-\mathrm{R}]^{+}(\mathrm{R}=\mathrm{Me}, n \mathrm{Pr}$, pentyl $)$ cationic species and including a solvent model. Of the three possible isomers of $\mathrm{Al} / \mathrm{Zr}$ heterobimetallic complexes derived from the cationic species $[\mathrm{rac}-\{\mathrm{EBTHI}\} \mathrm{Zr}-\mathrm{R}]^{+}$and Al-1, only one was identified, on kinetic and thermodynamic grounds, as the key intermediate. The DFT study also unveiled that (i) insertion of ethylene into the $\mathrm{Zr}$-alkyl bond of the growing PE chain is accompanied by a reversible decoordination of the Al-vinyl transfer agent (AVTA), (ii) the vinyl 1,2coordination/insertion of the alkenyl moieties of Al-1 into the $\mathrm{Zr}$-alkyl bond, resulting in the formation of branching, is in direct kinetic competition with the insertion of ethylene, and (iii) the re-coordination of the AVTA after either insertion step is thermodynamically favored and mostly responsible for the transmetallation phenomenon.
\end{abstract}




\section{INTRODUCTION}

Behavior of polymers during processing is known to be strongly dependent on their properties such as molecular weight $\left(M_{\mathrm{w}}\right)$, polydispersity $\left(M_{\mathrm{w}} / M_{\mathrm{n}}\right)$ and, more generally, their molecular architecture (linear, branched or cross-linked). The development of single-site catalyst technology has allowed the production of polyethylene (PE) with high molecular weight and narrow polydispersity. ${ }^{1}$ Although these characteristics confer excellent mechanical properties, such polymers suffer from poor processability due to their low elasticity and melt viscosity. In the 1990s, it has been shown that these properties can be improved by introducing long-chain branching (LCB) to linear PEs. ${ }^{2,3,4}$ Generally, LCB-polymers can be produced by post-reactor technologies such as high-energy electron beam irradiation, ${ }^{5,6}$ peroxide curing $^{7,8,9,10}$ and grafting. ${ }^{11}$ Yet, because of the radical mechanisms involved in these treatments, ample control over LCB formation is rather impossible; hence, polymers with complex structures are obtained in those cases. In-reactor technologies such as copolymerization of ethylene with either in situ-formed or previously isolated macromonomers, ${ }^{12,13}$ or with a non-conjugated $\alpha, \omega$-diene ${ }^{14,15,16,17,18,19,20,21,22,23}$ have also been developed. Nevertheless, only a limited number of catalyst systems have been shown to efficiently generate and incorporate macromonomers, while the second approach is limited by the rather scarce availability of $\alpha, \omega$-dienes and by the uneven distribution of LCB in the final polymers.

The detection of LCB (quantification, nature) is a difficult task, ${ }^{24}$ for which three main different techniques have been employed: (1) solution ${ }^{13} \mathrm{C}$ NMR spectroscopy, (2) size exclusion chromatography coupled with multi-angle laser light scattering (SEC-MALLS), and (3) melt rheological measurements. NMR spectroscopy suffers from the limited sensitivity (largely beyond that where rheological effects can be observed) and the hard/impossible discrimination between short- and long-chain branches, while costly apparatus are required 
for the second technique. ${ }^{25}$ On the other hand, melt rheological measurements proved to be very sensitive, enabling to evidence the presence of quite low contents of LCB. ${ }^{26,27,28}$

Recently, researchers at ExxonMobil have claimed in a patent the use of the hydroalumination product from diisobutylaluminum hydride (DIBAL-H) and 1,7-octadiene (referred to as "Al-octenyl" (Al-1)) as a promoter in the zirconocene-catalyzed polymerization of ethylene. ${ }^{29}$ Formation of LCB-PE was surmised, although no direct correlation with the Al promoter was made. In such a scenario, it can be assumed that LCB may originate from the $(1,2-)$ insertion of a pending oct-7-enyl moiety into the $\mathrm{Zr}-\mathrm{C}$ bond of a growing polymer chain, followed by $\mathrm{Al} \rightarrow \mathrm{Zr}$ transmetallation, eventually generating a growing side-chain (Scheme 1). On the contrary, protonolysis of the intermediate species (during quenching/workup) would lead to the formation of $n$-hexyl short-chain branches (SCB). Although industrially-promising, this approach suffers from drawbacks to decipher the nature of possible LCB and its mechanistic origin. In fact, the co-reactant consists of a mixture of mono-, di- and trisubstituted Al-oct-7-enyl species rather than of only one discrete species and, due to the similar nature of the alkenyl chains, discrimination between LCB and SCB in the final polymer cannot be performed by means of ${ }^{13} \mathrm{C}$ NMR spectroscopy. In a very recent study, various bis(alkenyl)-Zn reagents were used as chain-transfer agents (CTA) in \{pyridylamido\}-hafnium-catalyzed ethylene/ $\alpha$-olefin copolymerization, affording the corresponding LCB products. ${ }^{30}$ Yet, the methodology remains widely unexplored since, to our knowledge, excepting the above example, no reports are available in the open literature concerning neither Al-based reagents nor other M-alkenyl compounds.

Herein, we report on the synthesis of LCB-PEs mediated by $i \mathrm{BuAl}$ (oct-7-en-1-yl) $(\mathrm{Al}-$ 1) as co-reactant and their characterization by ${ }^{13} \mathrm{C}$ NMR spectroscopy and melt rheology. We highlight the efficiency of Al-alkenyl reactants as LCB promoters, which operate via a 
tandem mechanism involving both coordination/insertion and transmetallation reactions, as corroborated by extensive DFT computations.

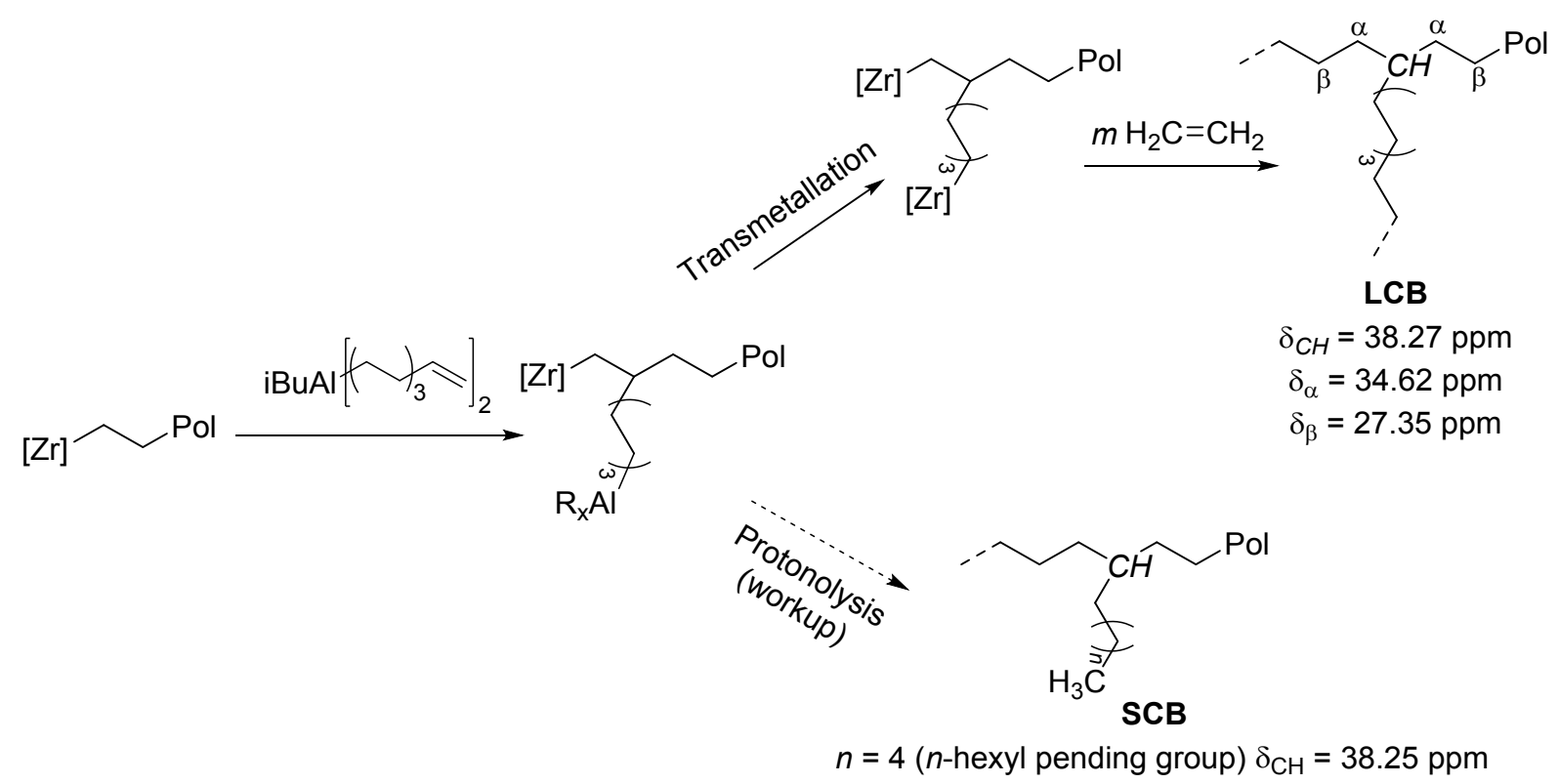

Scheme 1. Possible generation pathway and ${ }^{13} \mathrm{C}$ NMR spectroscopic fingerprint of short- (SCB) and long-chain branching (LCB) obtained in the presence of Al-alkenyl co-reactant (Pol= polymeryl chain). ${ }^{31}$

\section{RESULTS AND DISCUSSION}

Synthesis of Al-octenyl reagents. In order to prepare a mixed, well-defined isobutyl/oct-7-en-1-yl aluminum derivative, the hydroalumination reaction between DIBAL$\mathrm{H}$ and a large excess of 1,7-octadiene was studied under the reported conditions (Scheme 2). ${ }^{29}$ The average composition of the reaction mixture was assessed by ${ }^{1} \mathrm{H}$ NMR spectroscopy, through integration of the signals corresponding to the Al- $\mathrm{CH}_{2}$ (-octenyl) and $\mathrm{Al}-\mathrm{CH}_{2}\left(-{ }^{i} \mathrm{Bu}\right)$ groups $\left(\delta_{\mathrm{H}} 0.45\right.$ and $0.25 \mathrm{ppm}$, respectively; Figure S1). A series of signals corresponding to side-products was also detected. The principal side-product, identified as 7methylenepentadeca-1,14-diene, can result from the 1,2-insertion of an octenyl moiety into $\mathrm{Al}-\mathrm{C}$ bond followed by $\beta-\mathrm{H}$ elimination. 


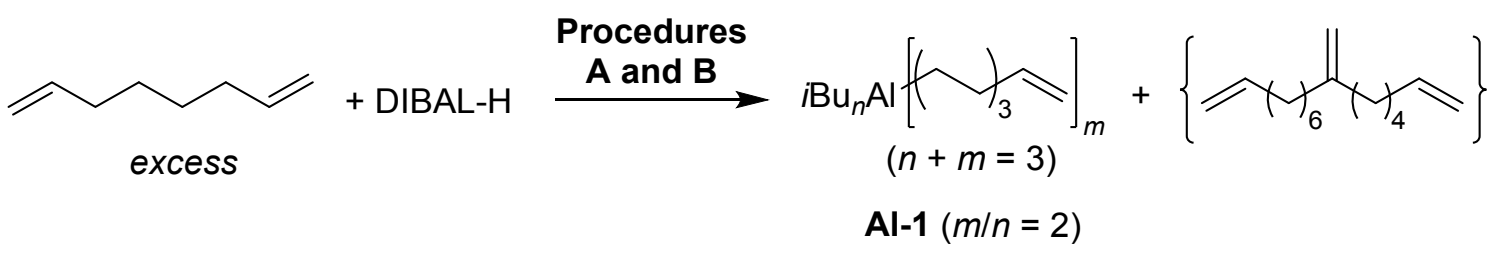

Procedure $\mathbf{A}:(1) 110^{\circ} \mathrm{C}, 1 \mathrm{~h} ;(2) 70{ }^{\circ} \mathrm{C}, 16 \mathrm{~h}$

B : $85^{\circ} \mathrm{C}, 16 \mathrm{~h}$

Scheme 2. Synthesis of Al-1.

The amount of side-product was determined from the ratio of the signal area at $\delta_{\mathrm{H}} 4.82$ ppm (terminal $=\mathrm{CH}_{2}$ protons) to the total area of the $\mathrm{CH}_{2}-\mathrm{Al}$ signals. Complete removal by a high-vacuum distillation of the side-product failed. Therefore, the original reaction conditions were optimized to minimize the formation of the undesired compound. Thus, by performing the reaction under slightly modified conditions (Procedure B: $85^{\circ} \mathrm{C}$, reaction time $16 \mathrm{~h}$ ), the targeted product Al-1 exhibiting the octenyl $/ \mathrm{Bu}$ ratio $(\mathrm{m} / \mathrm{n})$ close to 2 was obtained in a selective and reproducible manner (ESI, Figure S2).

Polymerization of ethylene catalyzed by homogeneous rac$\{$ EBTHI $\} Z_{\mathbf{Z C l}}$ /MAO/Al-alkenyl systems. For this investigation, $r a c-\{\mathrm{EBTHI}\} \mathrm{ZrCl}_{2}(\mathbf{Z r}-\mathbf{1}$, Figure 1) was selected as pre-catalyst. The polymerization of ethylene in the presence of $\mathbf{Z r}-\mathbf{1}$ /MAO/Al-1 system was studied (Table 1). Compared to the benchmark reaction conducted without Al-promoter (entry 1), significantly lower productivities were achieved for the reactions performed at $40{ }^{\circ} \mathrm{C}$ (entries 2 and 3). The polymers isolated in these runs (PE2 and PE3) exhibited poor solubility in 1,3,5-trichlorobenzene at $135{ }^{\circ} \mathrm{C}$ and lower $T_{\mathrm{m}}$ and $T_{\text {cryst }}$ values (126-128 ${ }^{\circ} \mathrm{C}$ and $114{ }^{\circ} \mathrm{C}$, respectively). The insolubility of these materials was attributed to the alleged formation of crosslinks promoted by Al-1. A soluble sample (PE4) characterized by SEC was obtained by carrying out the reaction at $60{ }^{\circ} \mathrm{C}$ in the presence of $\mathrm{H}_{2}$ (entry 4). The low $M_{\mathrm{w}}$ value of the polymer is likely due to the capability of both $\mathrm{H}_{2}$ and $\mathbf{A l - 1}$ 
to act as chain-transfer reagents, while the formation of crosslinks was probably suppressed due to the higher temperature, compared to entries 2 and $3\left(60\right.$ and $40{ }^{\circ} \mathrm{C}$, respectively).

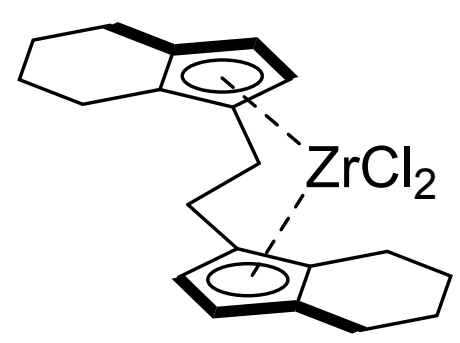

Figure 1. Structure of $r a c-\{\mathrm{EBTHI}\} \mathrm{ZrCl}_{2}(\mathrm{Zr}-\mathbf{1})$.

Table 1: Polymerization of ethylene in the presence of $r a c-\{\mathrm{EBTHI}\} \mathrm{ZrCl}_{2} / \mathrm{MAO} / \mathbf{A l}-\mathbf{1}$. $^{\mathrm{a}}$

\begin{tabular}{|c|c|c|c|c|c|c|c|c|}
\hline Entry & $\begin{array}{c}\text { Sample } \\
\text { ID }\end{array}$ & $\begin{array}{c}\text { Al-1 } \\
{[\mathrm{Al} / \mathrm{Zr}]}\end{array}$ & $\begin{array}{c}T_{\text {polym }} \\
{\left[{ }^{\circ} \mathrm{C}\right]}\end{array}$ & $\begin{array}{c}\text { Productivity } \\
{\left[\mathrm{kg}_{\mathrm{Pol}} / \mathrm{kg}_{\mathrm{Zr}}\right]}\end{array}$ & $\begin{array}{l}T_{\mathbf{m}}{ }^{\mathrm{c}} \\
{\left[{ }^{\circ} \mathrm{C}\right]}\end{array}$ & $\begin{array}{c}T_{\text {cryst }}{ }^{c} \\
{\left[{ }^{\circ} \mathrm{C}\right]}\end{array}$ & $\begin{array}{c}\boldsymbol{M}_{\mathbf{w}}{ }^{\mathrm{d}} \\
{\left[\times 10^{-3}\right]}\end{array}$ & $M_{\mathrm{w}} / M_{\mathrm{n}}^{\mathrm{d}}$ \\
\hline $1^{\mathrm{e}}$ & PE1 & - & 60 & 8,170 & 135.8 & 117.8 & 141.3 & 3.3 \\
\hline 2 & PE2 & 500 & 40 & 3,330 & 126.8 & 114.6 & \multirow{2}{*}{\multicolumn{2}{|c|}{$\begin{array}{l}\text { Insoluble } \\
\text { Insoluble }\end{array}$}} \\
\hline $3^{\mathrm{f}}$ & PE3 & 500 & 40 & 5,170 & 128.5 & 114.5 & & \\
\hline $4^{\mathrm{f}}$ & PE4 & 500 & 60 & 7,670 & 127.7 & 115.5 & 94.0 & 3.6 \\
\hline
\end{tabular}

a Polymerization conditions: $300 \mathrm{~mL}-$ high pressure glass reactor; solvent: toluene, $150 \mathrm{~mL}$; $\mathrm{P}($ ethylene $)=4$ bar; time $=15 \mathrm{~min} ;[\mathrm{Zr}]_{0}=10 \mu \mathrm{M},\left[\mathrm{Al}_{\mathrm{MAO}}\right] /[\mathrm{Zr}]_{0}=4,500 .{ }^{c}$ Determined by DSC from second run. ${ }^{d}$ Determined by SEC. ${ }^{\mathrm{e}}\left[\mathrm{Al}_{\mathrm{MAO}}\right] /[\mathrm{Zr}]_{0}=5,000 .{ }^{\mathrm{f}} \mathrm{H}_{2}=800 \mathrm{ppm}$.

In order to study the effect of Al-1 on the formation of LCB, the soluble samples (PE1 and PE4) were analyzed by ${ }^{13} \mathrm{C}$ NMR spectroscopy. A signal compatible with the $C \mathrm{H}$ - group at the branching point of the LCB $\left(\delta_{C H} 38.22 \mathrm{ppm}\right)^{31}$ was observed in the spectrum of the sample synthesized with MAO only (Figure S3). Based on the integration of this signal, the LCB density was estimated to be $0.3 / 10,000 \mathrm{C}$. However, some resonances related to the sample oxidation (that allegedly occurred under the analytical conditions, i.e. $135^{\circ} \mathrm{C}$ ) were also detected. The presence of these resonances may affect the accuracy of LCB quantification, hence the value found must be considered as indicative. The ${ }^{13} \mathrm{C}$ NMR spectroscopic analysis of the PE prepared in the presence of Al-1 proved purposeless; indeed, the technique is unable to distinguish the tertiary carbon atoms of side-chains longer than 6 carbons (Scheme 1; Figures S4 and S5). ${ }^{26,31}$ Hence, the unambiguous discrimination between 
LCB and $n$-hexyl-branches, possibly derived from the insertion of Al-1 followed by hydrolysis, could not be performed. Moreover, ${ }^{13} \mathrm{C}$ NMR spectroscopy is poorly suited to low LCB content (vide infra). ${ }^{26}$

In order to overcome these limitations, both samples were further examined by melt rheology. For this purpose, the trend of the modulus of the complex viscosity $\left(\left|\eta^{*}\right|\right)$ as a function of the angular frequency $(\omega)$ was first investigated (Figure $2 a)$. In the whole range of frequencies considered $\left(0.1-250 \mathrm{rad} . \mathrm{s}^{-1}\right)$, the viscosity of the PE synthesized with MAO only (PE1, entry 1) was higher than that of the sample prepared in the presence of Al-1 (PE4, entry 4). The van Gurp-Palmen (vGP) plot was next considered (Figure 2b). In this representation, curves of purely linear polymers tend to a phase angle $(\delta)$ of $90^{\circ}$ at low $\left|\mathrm{G}^{*}\right|$, while lower angles are observed upon increasing the LCB density and/or broadening of the molecular weight distribution (MDW). ${ }^{32,33}$ The curves for both PE1 and PE4 were found to be far from the linear case, which is consistent with the above ${ }^{13} \mathrm{C}$ NMR spectroscopy results and a significant presence of LCB. However, the polymer prepared with Al-1 showed lower phase angle than that of the PE synthesized with MAO only. Given that the polydispersity values of these two polymers were found to be rather similar $\left(M_{\mathrm{w}} / M_{\mathrm{n}}=3.3-3.6\right)$, the drop of $\delta$ could be ascribed only to an increase of LCB content. The presence of LCB also in the PE produced in the absence of the Al-alkenyl promoter is not surprising, since the pre-catalyst herein employed is known to promote the formation of branches to a certain extent via macromonomer insertion. ${ }^{34}$ 


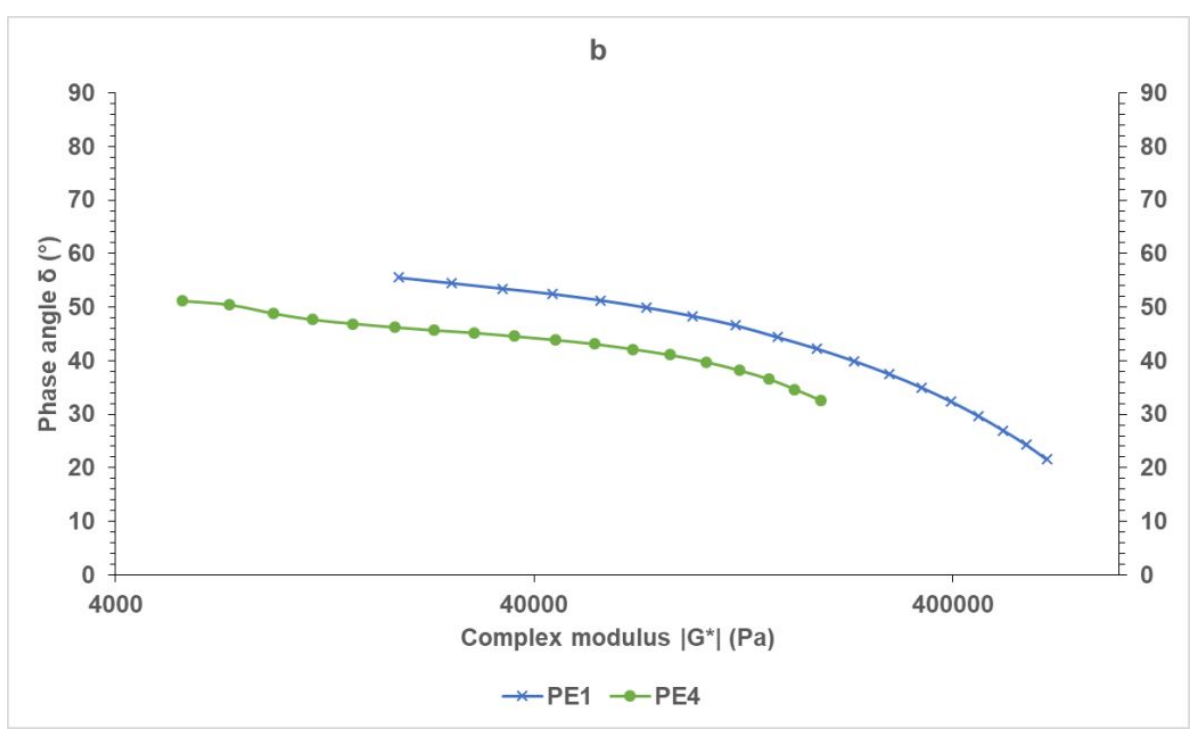

Figure 2. Rheological properties of PE samples obtained with $\mathbf{Z r - 1 / M A O / A l - 1}$ systems: (a) complex viscosity $\left(\left|\eta^{*}\right|\right)$ vs angular frequency $(\omega)$ plot; $(\mathbf{b})$ van Gurp-Palmen plot. Shear strain $(\gamma) 10 \%$, angular frequencies $(\omega)$ from 0.1 to $250 \mathrm{rad} \cdot \mathrm{s}^{-1}, \mathrm{~T}=190^{\circ} \mathrm{C}$.

\section{Polymerization of ethylene catalyzed by heterogeneous supp-rac-} $\{$ EBTHI $\} \mathbf{Z r C l}_{2} / \mathbf{T I B A L} / \mathbf{A l}-1$ systems. The ability of Al-1 to promote LCB was also explored under heterogeneous conditions by employing the MAO on silica-supported version of the catalyst, namely supp-Zr-1. A first set of reactions was performed in a $300 \mathrm{~mL}-$ reactor at $80^{\circ} \mathrm{C}$ in the presence of $800 \mathrm{ppm}$ of $\mathrm{H}_{2}$ as re-activator/chain-transfer agent (Table 2). 
Table 2. Polymerization of ethylene in the presence of supp- $\mathbf{Z r - 1} /$ TIBAL/Al-1. ${ }^{\text {a }}$

\begin{tabular}{|c|c|c|c|c|c|c|c|c|}
\hline Entry & $\begin{array}{c}\text { Sample } \\
\text { ID }\end{array}$ & $\begin{array}{l}\text { TIBAL } \\
\text { [ppm] } \\
(A l / Z r)\end{array}$ & $\begin{array}{c}\text { Al-1 } \\
{[\mathrm{ppm}]} \\
(A l / Z r)\end{array}$ & $\begin{array}{c}\text { Productivity } \\
{\left[\mathrm{kg}_{\mathrm{Pol}} / \mathrm{kg}_{\mathrm{cat}}\right]}\end{array}$ & $\begin{array}{c}\boldsymbol{T}_{\mathbf{m}}^{b} \\
{\left[{ }^{\circ} \mathrm{C}\right]}\end{array}$ & $\begin{array}{c}\boldsymbol{T}_{\text {cryst }}{ }^{b} \\
{\left[{ }^{\circ} \mathrm{C}\right]}\end{array}$ & $\begin{array}{c}\boldsymbol{M}_{\mathbf{w}}^{c} \\
{\left[\times 10^{-3}\right]}\end{array}$ & $M_{\mathrm{w}} / M_{\mathrm{n}}^{\mathrm{c}}$ \\
\hline 1 & PE5 & $\begin{array}{l}1,000 \\
(350)\end{array}$ & - & 135 & 133.8 & 118.6 & 67.4 & 3.0 \\
\hline 2 & PE6 & - & $\begin{array}{l}20 \\
(7)\end{array}$ & 200 & 134.4 & 118.9 & 71.7 & 2.9 \\
\hline 3 & PE7 & - & $\begin{array}{l}100 \\
(35)\end{array}$ & 140 & 133.8 & 118.8 & 67.3 & 2.9 \\
\hline 4 & PE8 & - & $\begin{array}{c}500 \\
(175)\end{array}$ & 140 & 132.6 & 118.0 & 73.0 & 3.3 \\
\hline 5 & PE9 & - & $\begin{array}{l}1,000 \\
(350)\end{array}$ & 160 & 132.6 & 117.8 & 67.7 & 3.3 \\
\hline 6 & PE10 & - & $\begin{array}{l}2,000 \\
(700)\end{array}$ & 160 & 132.0 & 118.2 & 63.1 & 3.1 \\
\hline 7 & PE11 & - & $\begin{array}{l}3,000 \\
(1050)\end{array}$ & 165 & 132.1 & 118.1 & 61.2 & 3.2 \\
\hline 8 & PE12 & $\begin{array}{c}500 \\
(175)\end{array}$ & $\begin{array}{c}500 \\
(175)\end{array}$ & 160 & 133.2 & 118.5 & 70.7 & 3.2 \\
\hline 9 & PE13 & $\begin{array}{c}750 \\
(260)\end{array}$ & $\begin{array}{l}250 \\
(90)\end{array}$ & 160 & 133.3 & 118.3 & 68.9 & 3.1 \\
\hline 10 & PE14 & $\begin{array}{l}250 \\
(90)\end{array}$ & $\begin{array}{c}750 \\
(260)\end{array}$ & 130 & 132.6 & 118.3 & 67.5 & 3.3 \\
\hline
\end{tabular}

${ }^{a}$ Polymerization conditions: solvent: toluene, $150 \mathrm{~mL} ; T_{\mathrm{pol}}=80^{\circ} \mathrm{C}$; P(ethylene $)=4$ bar; time $=60 \mathrm{~min}$; suppZr-1 $=35 \mathrm{mg}\left([\mathrm{Zr}]_{0}=14 \mu \mathrm{M}\right) ; \mathrm{H}_{2}=800 \mathrm{ppm} .{ }^{b}$ Determined by DSC from second run. ${ }^{c}$ Determined by SEC.

For comparison purposes, a benchmark polymerization was carried out with only TIBAL as scavenger (PE5). Ethylene polymerizations were performed by increasing progressively the amount of Al-1 (PE6-PE11) and also by using mixtures of TIBAL/Al-1 (PE12-PE14). All polymerizations showed the same productivity, regardless of the amount of Al-1 used. In addition, thermal properties of the PEs were found to be similar. No direct correlation was found between the amount of AVTA introduced and the molecular weight (and MWD) of the resulting polymer, thus arguing against chain-transfer processes operating efficiently. On the other hand, remarkably, the rheological fingerprints of the samples were found to be highly affected by the use of Al-1. In fact, all samples prepared with the co-reactant exhibited higher $\left|\eta^{*}\right|$ at low frequencies and stronger shear thinning as compared with those PE5 (Figure 3a,b). Moreover, the magnitude of such variations was consistent with the amount of Al-1 
employed. Since, in this case, $M_{\mathrm{w}}$ effect can be excluded, the different rheological behaviors can be confidently attributed entirely to LCB formation. This assumption was confirmed by the vGP plots (Figure 3c,d). It has to be noted that all polymers have a decreasing delta towards the points with the lowest frequency. We assume to be in proximity of a minimum which cannot be observed due to the limited range of frequencies investigated. The presence of a minimum in vGP plots has been already reported in the literature, for example by Stadler et al. ${ }^{28,35,36,37}$ At the same time, no meaningful information could be obtained upon trying to correlate the double logarithmic derivative of the viscosity function $\left(\operatorname{dlog}\left|\eta^{*}\right| / d \log \omega\right)$ with the phase angle $\delta$ (Figure S6). ${ }^{38}$
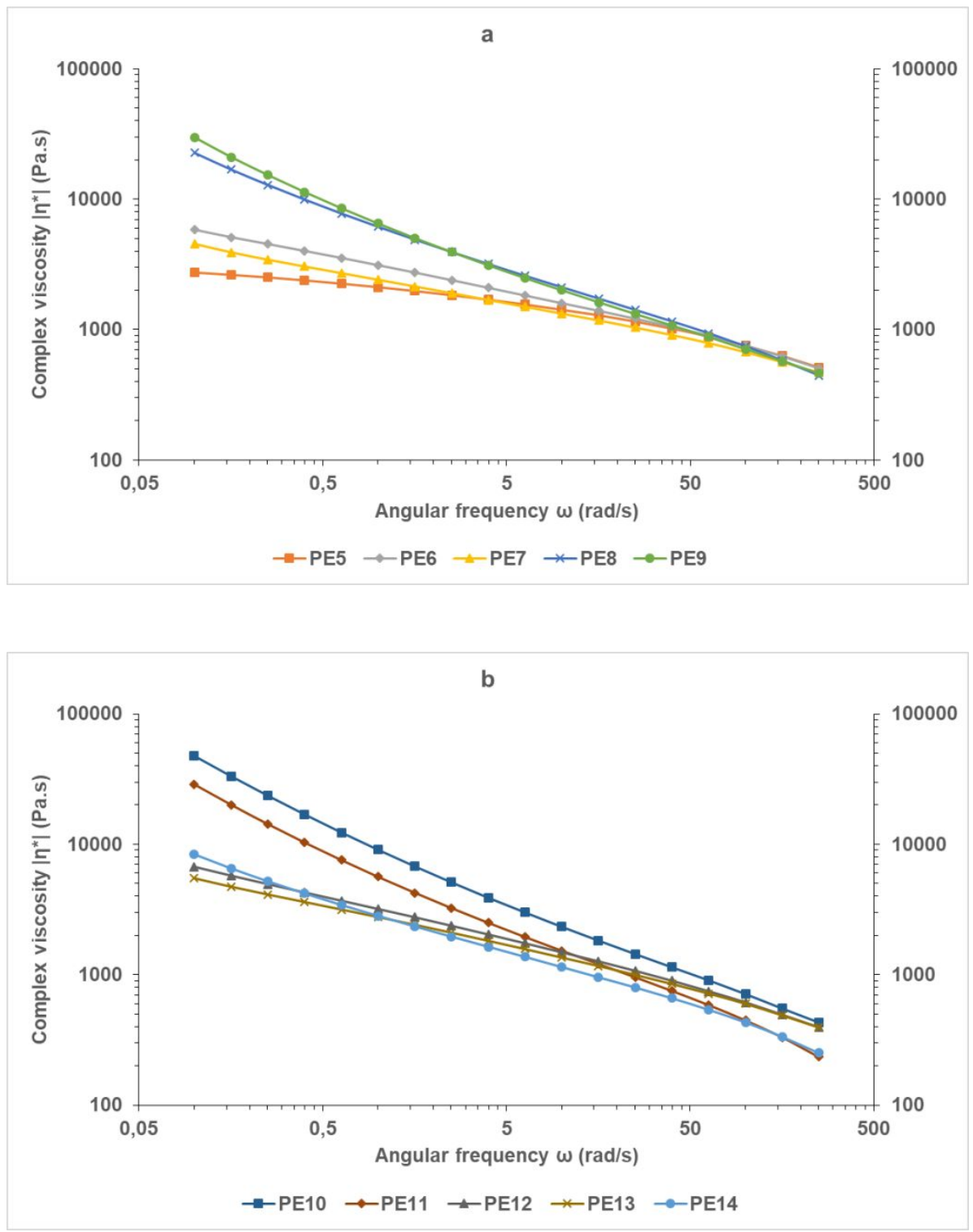
C

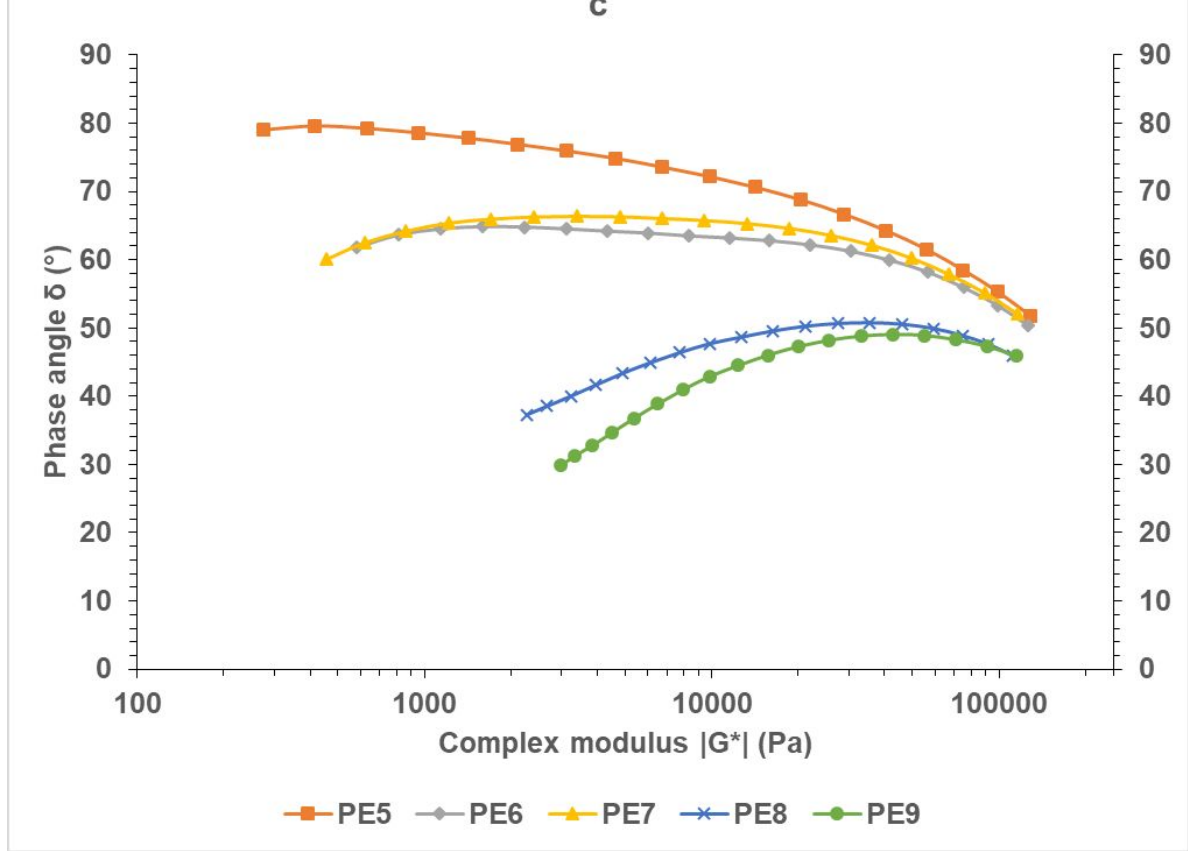

d

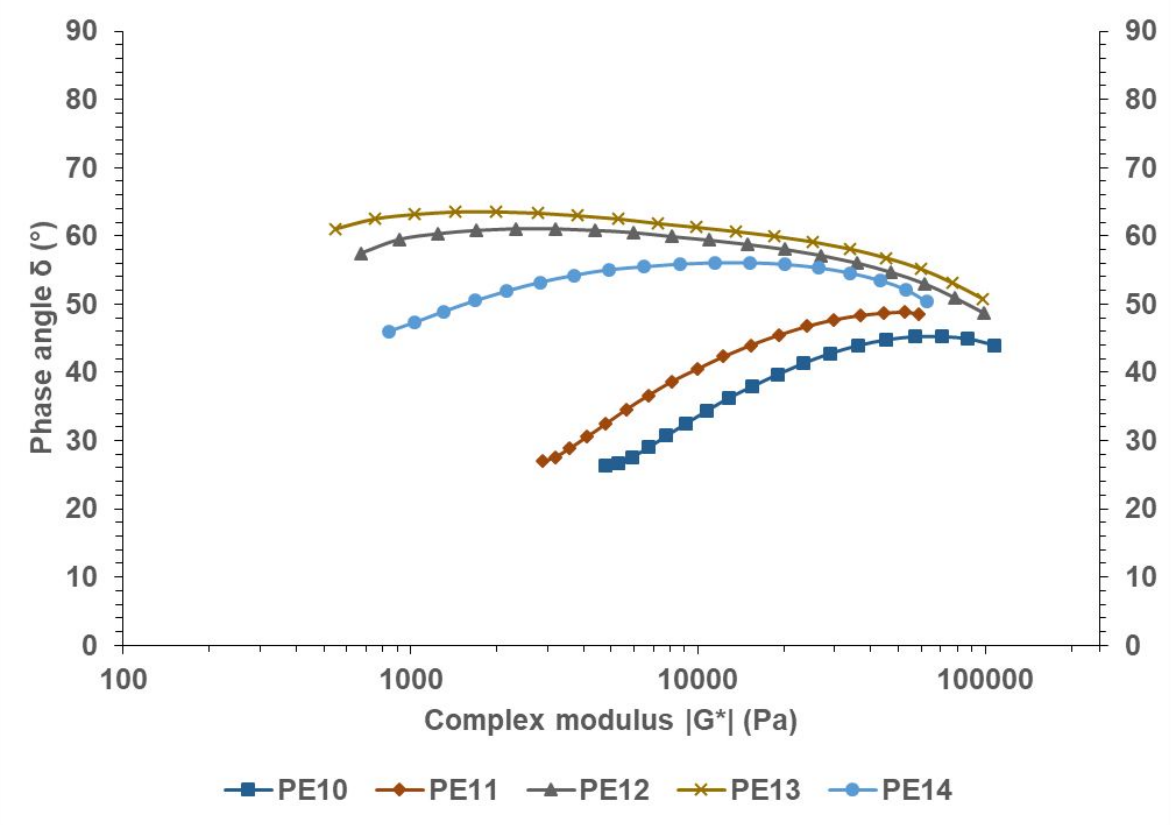

Figure 3. Rheological properties of the PEs obtained with supp-Zr-1/TIBAL/Al-1 systems: (a, b) complex viscosity $\left(\left|\eta^{*}\right|\right)$ vs angular frequency $(\omega)$ plot, $(\mathbf{c}, \mathbf{d})$ van Gurp-Palmen plot. Shear strain $(\gamma) 10 \%$, angular frequencies $(\omega)$ from 0.1 to $250 \mathrm{rad} \cdot \mathrm{s}^{-1}, \mathrm{~T}=190{ }^{\circ} \mathrm{C}$.

The effect of $\mathrm{H}_{2}$ on the process and polymer properties was also investigated. For this purpose, a second series of polymerization tests was carried out in the presence of a fixed amount of Al-1 and variable amounts of $\mathrm{H}_{2}$ (Table 3). In order to achieve higher activity, 1- 
hexene was added as co-monomer (cf. entries 3 and 4). ${ }^{39}$ Under these reaction conditions, a drop of productivity and a decrease of the polymer molecular weight were observed, as the amount of $\mathrm{H}_{2}$ in feed was increased; in fact, if too much $\mathrm{H}_{2}$ is added, it rather behaves as a chain-terminating agent. On the other hand, the $T_{\mathrm{m}}$ and polydispersity values were not significantly altered (except for the run conducted in the absence of the co-monomer), spanning in the ranges of $120-122{ }^{\circ} \mathrm{C}$ and of $2.8-3.3$, respectively. Excessively increasing the amount of $\mathrm{H}_{2}$ had also a detrimental effect on LCB formation, as highlighted by their corresponding vGP plots (Figure 4). ${ }^{40}$ In that case, the phase angle $\delta$ increased with the amount of $\mathrm{H}_{2}$ introduced, suggesting a drop of LCB density. ${ }^{38,41}$ This could be attributed to the occurrence of side processes (chain-transfer, termination) competing at higher $\mathrm{H}_{2}$ concentrations with monomer insertion and transmetallation reactions, preventing both the growth of the main PE chain and LCB formation.

Table 3. Effect of $\mathrm{H}_{2}$ concentration on the polymerization of ethylene in the presence of suppZr-1/Al-1. ${ }^{\mathrm{a}}$

\begin{tabular}{ccccccccc}
\hline Entry & $\begin{array}{c}\text { Sample } \\
\text { ID }\end{array}$ & $\begin{array}{c}\text { Co-reactant } \\
{[\mathrm{ppm}]}\end{array}$ & $\begin{array}{c}\mathbf{H}_{\mathbf{2}} \\
{[\mathrm{ppm}]}\end{array}$ & $\begin{array}{c}\text { Productivity } \\
{\left[\mathrm{kg}_{\mathrm{Pol}} / \mathrm{kg}_{\mathrm{cat}}\right]}\end{array}$ & $\begin{array}{c}\boldsymbol{T}_{\mathbf{m}}{ }^{b} \\
{\left[{ }^{\circ} \mathrm{C}\right]}\end{array}$ & $\begin{array}{c}\boldsymbol{M}_{\mathbf{n}}{ }^{c} \\
{\left[\times 10^{-3}\right]}\end{array}$ & $\begin{array}{c}\boldsymbol{M}_{\mathbf{w}}{ }^{c} \\
{\left[\times 10^{-3}\right]}\end{array}$ & $\boldsymbol{M}_{\mathbf{w}} / \boldsymbol{M}_{\mathbf{n}}{ }^{\mathrm{c}}$ \\
\hline 1 & PE15 & TIBAL [100] & 800 & 4.5 & 121 & 30 & 85 & 2.9 \\
2 & PE16 & Al-1 [200] & 500 & 4.0 & 121 & 37 & 122 & 3.3 \\
3 & PE17 & Al-1 [200] & 800 & 3.8 & 120 & 30 & 95 & 3.2 \\
$4^{d}$ & PE18 & Al-1 [200] & 800 & 1.2 & 132 & 27 & 94 & 3.4 \\
5 & PE19 & Al-1 [200] & 1,000 & 3.2 & 121 & 25 & 77 & 3.1 \\
6 & PE20 & Al-1 [200] & 1,500 & 3.0 & 122 & 18 & 52 & 2.9 \\
7 & PE21 & Al-1 [200] & 2,000 & 2.9 & 122 & 15 & 42 & 2.8 \\
8 & PE22 & Al-1 [200] & 2,500 & 2.6 & 122 & 13 & 36 & 2.8 \\
\hline
\end{tabular}

${ }^{a}$ Polymerization conditions: solvent: iso-butane $41.25 \mathrm{~g} ; T_{\mathrm{pol}}=85^{\circ} \mathrm{C}$; P(ethylene $)=25$ bar $(6 \mathrm{wt} \%) ; 1$-hexene $2.44 \mathrm{wt} \%$; time $=60 \mathrm{~min}$; supp-Zr-1 $=5.0 \mathrm{mg}\left([\mathrm{Zr}]_{0}=2.0 \mu \mathrm{M}\right) .{ }^{b}$ Determined by DSC from the second run. ${ }^{c}$ Determined by SEC. ${ }^{d}$ No 1 -hexene added. 


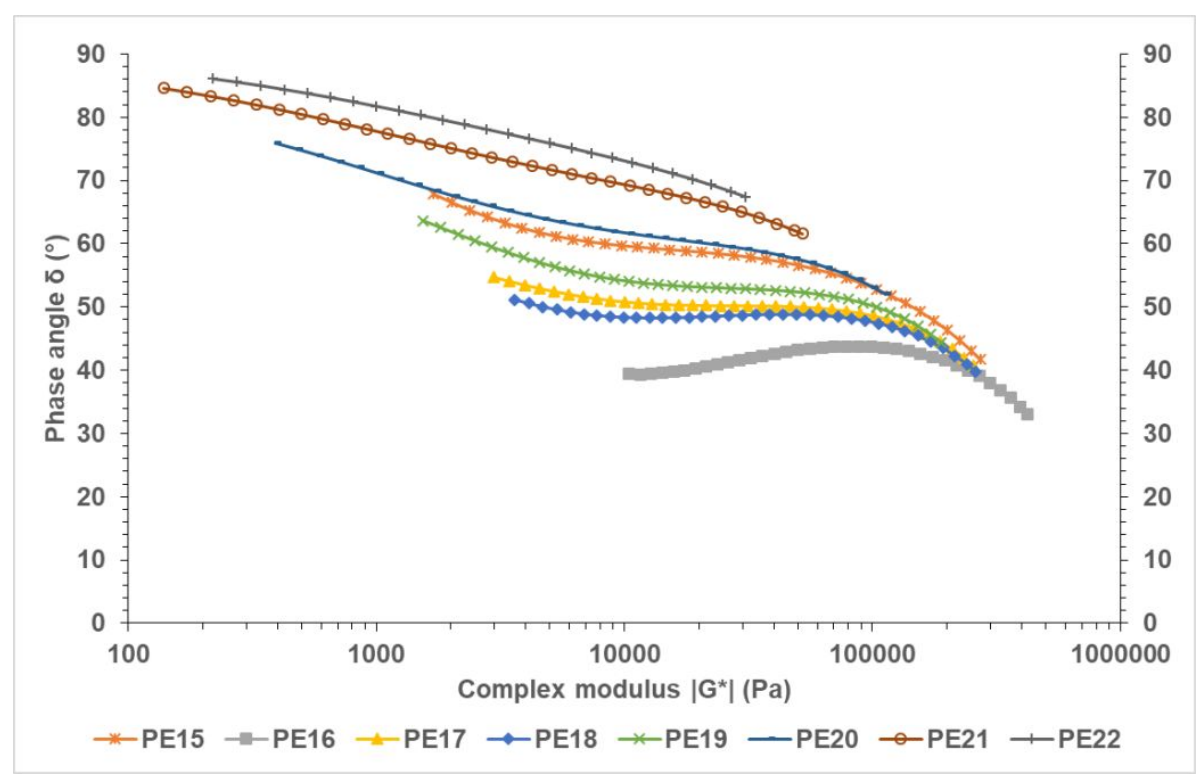

Figure 4. Van Gurp-Palmen plot of the PEs obtained with supp-rac- $\{\mathrm{EBTHI}\} \mathrm{ZrCl}_{2} / \mathrm{TIBAL} / \mathbf{A l}-\mathbf{1}$ system with different amounts of $\mathrm{H}_{2}$. Shear strain $(\gamma) 10 \%$, angular frequencies $(\omega)$ from 0.1 to $250 \mathrm{rad} \cdot \mathrm{s}^{-1}, T=190^{\circ} \mathrm{C}$.

The polymers isolated in entries 3 and 4 were further analyzed by ${ }^{13} \mathrm{C}$ NMR spectroscopy (Figures S4 and S5, respectively). Interestingly, the resonance diagnostic for LCB ( $\delta 38.27 \mathrm{ppm}$ ) was not observed, confirming the technique being unsuitable for the detection of low amounts of branches. ${ }^{26}$

DFT studies on the LCB formation. Usually, the influence of an organoaluminium reagent in the polymerization process is not taken into account by a standard computational model. This is due to the assumption that such a co-catalytic species simply delivers the alkyl group to initiate the polymerization. In this DFT study, we aimed at rationalizing the mechanism of formation for long-chain branches during polymerization of ethylene with rac$\{\mathrm{EBTHI}\} \mathrm{ZrCl}_{2}$ carried out in the presence of $i \mathrm{BuAl}$ (oct-7-en-1-yl) $)_{2}$ (Al-1) (Scheme 3). 
The first three ethylene insertions were computed with the cationic form of the active catalyst $[\mathrm{rac}-\{\mathrm{EBTHI}\} \mathrm{ZrMe}]^{+}$(Figure S8). The reaction was found to be favored both kinetically and thermodynamically (highest barrier of $6.8 \mathrm{kcal} \cdot \mathrm{mol}^{-1}$ for the first insertion and exothermic by $\sim 20 \mathrm{kcal} \cdot \mathrm{mol}^{-1}$ each step). This is in line with the experimental ability of the EBTHI-Zr catalyst to efficiently polymerize ethylene. However, the overall situation is different when Al-1 is introduced in the polymerization due to the presence of, not only an alkyl but also, alkenyl chains on the co-catalyst. It was then suggested that Al-1 could coordinate to the $[\mathrm{rac}-\{\mathrm{EBTHI}\} \mathrm{ZrMe}]^{+}$catalyst generating an $\mathrm{Al} / \mathrm{Zr}$ heterobimetallic species. Depending on the nature of the 'bridge' formed between the $\mathrm{Zr}$ and $\mathrm{Al}$ atoms, upon the binding of Al-1 to $[\mathrm{rac}-\{\mathrm{EBTHI}\} \mathrm{ZrMe}]^{+}$, three different isomers can be distinguished (Scheme 4). 
A comparison of the various coordination affinities between the three isomers and the parent $[\mathrm{rac}-\{\mathrm{EBTHI}\} \mathrm{ZrMe}]^{+}$system showed isomer $\mathbf{A}$ to be the most stabilized, with the bimetallic complex gaining $4.8 \mathrm{kcal} \cdot \mathrm{mol}^{-1}$. Although the stabilizing effect is rather small, the influence of the co-catalyst coordination on the ethylene polymerization needed to be investigated. It was found that two pathways for insertion of an ethylene monomer exist: after dissociation (Scheme 5) or whilst Al-1 remained coordinated (Figure S9). 


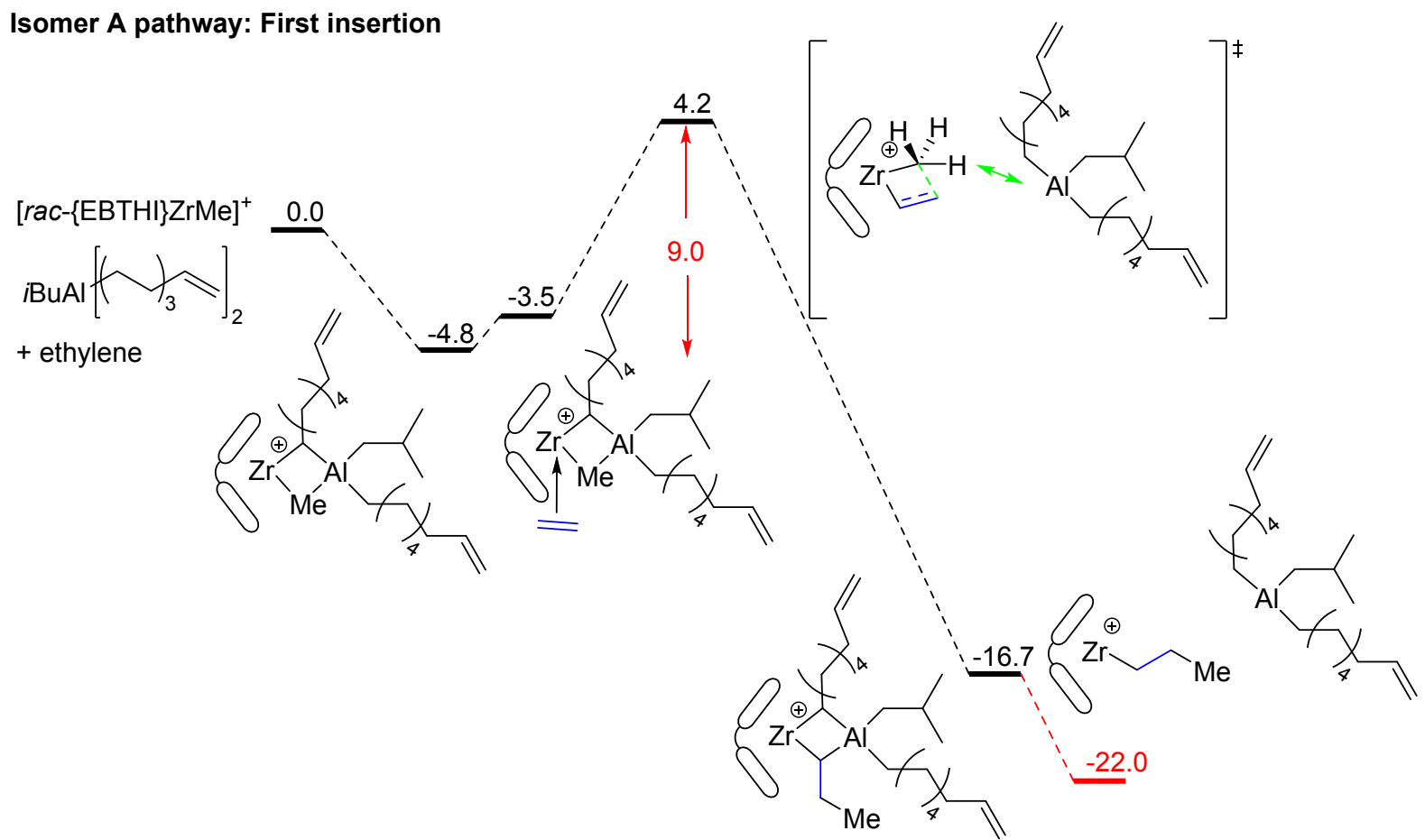

Scheme 5. The energy profile for the coordination of Al-1 to $[\mathrm{rac}-\{\mathrm{EBTHI}\} \mathrm{ZrMe}]^{+}$followed by the insertion of ethylene via a dissociative pathway. The re-coordination of the co-catalyst species is shown, forming the thermodynamically stable $[\mathrm{rac}-\{\mathrm{EBTHI}\} \mathrm{Zr}(n \mathrm{Pr})]^{+}$.

The two respective barriers for the first insertion of ethylene, once the co-catalyst is dissociated or remaining coordinated to the $[\mathrm{rac}-\{\mathrm{EBTHI}\} \mathrm{ZrMe}]^{+}$system, were 9.0 $\mathrm{kcal} \cdot \mathrm{mol}^{-1}$ and $46.0 \mathrm{kcal} \cdot \mathrm{mol}^{-1}$. In these cases, nucleophilic addition of ethylene occurs about the $\mathrm{Zr}-\mathrm{Me}$ or $\mathrm{Al}-\mathrm{Me}$ bond respectively. The non-dissociative profile (Figure S9) refers to the less likely insertion of ethylene caused by a nucleophilic addition from the methyl group towards the monomer - catalyst system. The 'classical insertion' refers to the addition of ethylene to the $\mathrm{Zr}-\mathrm{Me}$ bond once Al-1 has dissociated, via cleavage of the $\mathrm{Zr}-\mathrm{Me}-\mathrm{Al}$ bridge. As a result, the insertion of ethylene via a systematic dissociation of the co-catalyst is kinetically preferable (Figures S10 and S11). Interestingly, regardless of the pathway ethylene is inserted, the re-coordination of the co-catalyst is thermodynamically most favorable, affording the same $\left[\mathrm{rac}-\{\mathrm{EBTHI}\} \mathrm{Zr}-(n \text {-propyl)-Al(oct-7-en-1-yl })_{2} i \mathrm{Bu}\right]^{+}$bimetallic species. 
Figure 4. Transition state geometries for the first ethylene insertion: (top) the dissociation of Al-1 prior to ethylene insertion, (bottom) the non-dissociative transition state.

Because dissociation of the Al-1 species is favorable for ethylene insertions, a more thorough investigation into how this occurs was conducted. The mechanism of dissociation is thought to have two possibilities, identifying that either the Al-alkyl or Al-(oct-7-en-1-yl) bond is cleaved (Scheme 6). 
1.

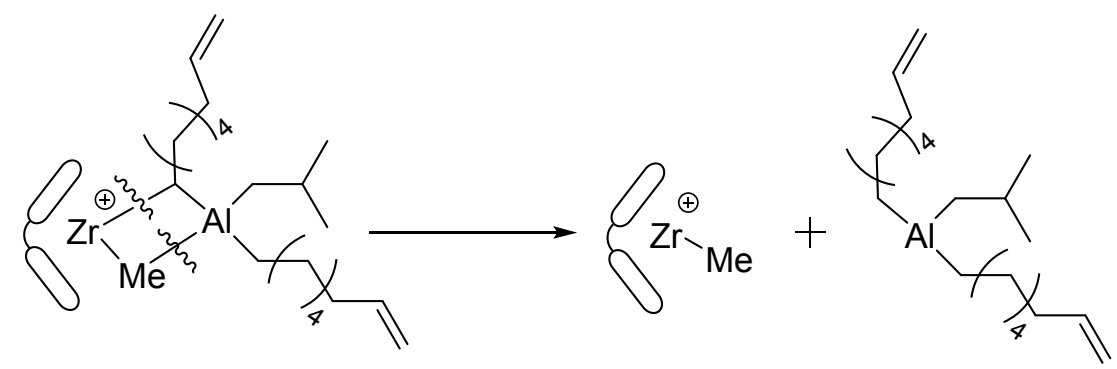

2.

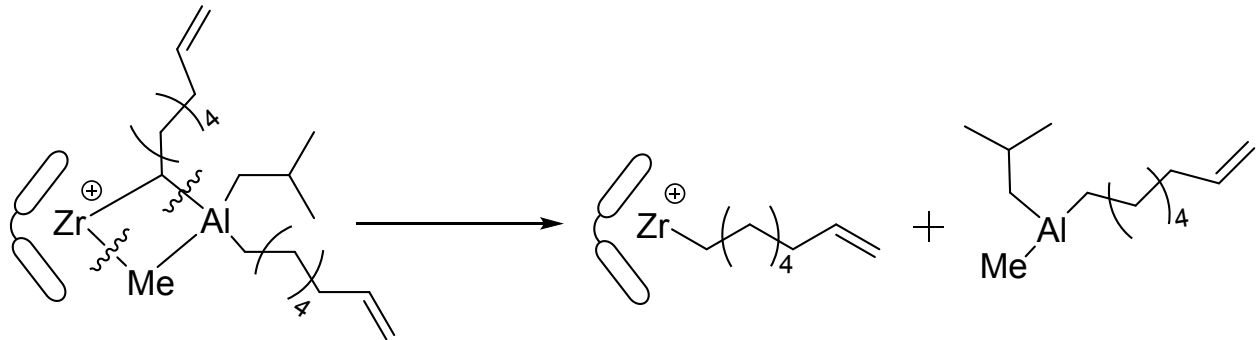

Scheme 6. The dissociation of Al-1 respective of: (1) Al-alkyl (1) or (2) Al-(oct-7-en-1-yl) bond cleavage. Note that the latter mechanism involves the transmetallation of the alkyl and alkenyl chains between $\mathrm{Al}$ and $\mathrm{Zr}$ centers.

Cleavage of the Al-(oct-7-en-1-yl) bond (pathway 2) owes to an alkenyl chain-shuttling from the co-catalytic species to the catalyst system forming the $\left[\right.$ rac- $\{\mathrm{EBTHI}\} \mathrm{Zr}-(\text { oct-7-en-1-yl) }]^{+}$ species. An investigation was conducted into the required energy input needed to cleave either the Al-methyl or Al-alkenyl bonds. It was concluded that the Al-alkenyl bond was slightly stronger, with a dissociation energy of $6 \mathrm{kcal} \cdot \mathrm{mol}^{-1}$ relative to $4.8 \mathrm{kcal} \cdot \mathrm{mol}^{-1}$ for the Al-methyl bond. A difference of $1.2 \mathrm{kcal} \cdot \mathrm{mol}^{-1}$ gives little concrete evidence of one bond cleavage being definitively favorable from the another but may offer insight into a competitive environment that allows the co-catalytic species to dissociate. An Al-alkenyl group transfer to form $\left[\mathrm{rac}-\{\mathrm{EBTHI}\} \mathrm{Zr}-(\text { oct-7-en-1-yl) }]^{+}\right.$species brings about a $\mathrm{Zr}$-polymeryl moiety with a terminal vinyl group after one step (considering the formation of the bimetallic species as a reference).

Considering the length of the alkenyl chain, an intramolecular cyclisation was considered and investigated. It was found that subsequent insertions of ethylene into the [ rac$\{$ EBTHI $\}$ Zr-(oct-7-en-1-yl) $]^{+}$chain are plausible (Scheme 7) and, although a cyclisation is 
feasible, it is kinetically less favorable than the adduct-less insertions of ethylene (with a corresponding transition state barrier difference of $7.2 \mathrm{kcal} \cdot \mathrm{mol}^{-1}$; Figure S12). This gives sufficient evidence to suggest that an Al-alkenyl chain transfer provides a significantly more facile one-step precursor to longer chain formations. In comparison to a cyclisation reaction, the ethylene insertions are far more likely and the adduct-less nature of this owes to a faster generation of a linear Zr-polymeryl species.

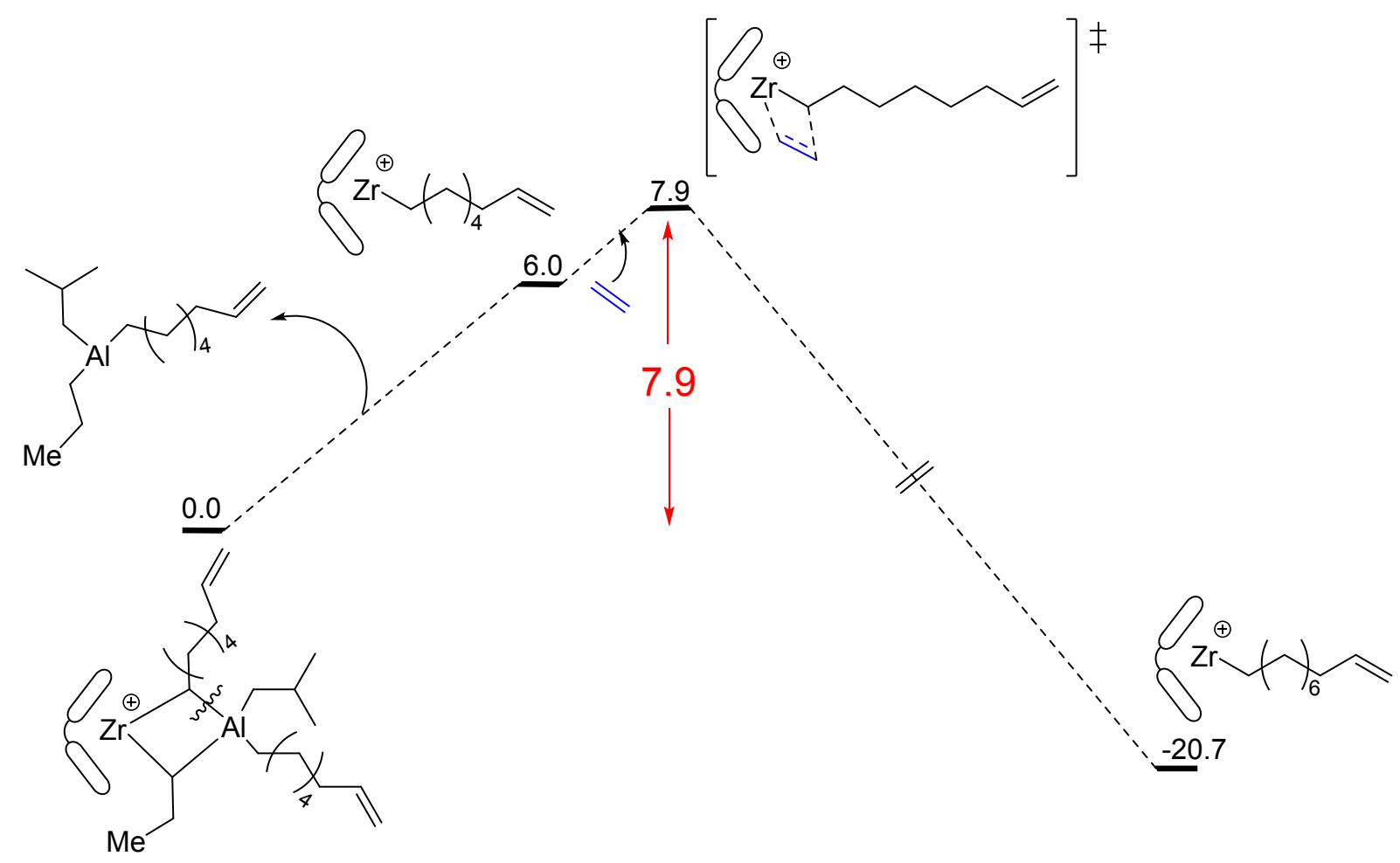

Scheme 7. The profile for an insertion of ethylene monomer to $\left[\mathrm{rac}-\{\mathrm{EBTHI}\} \mathrm{Zr}-(\mathrm{oct}-7 \text {-en-1-yl) }]^{+}\right.$formed via the cleavage of the Al-alkenyl bond and subsequent oct-7-en-1-yl group transfer. Note, the adduct-less interaction of the monomer suggests a more rapid insertion of ethylene.

The cleavage of the Al-alkyl bond results in a competition between the insertion of ethylene monomer and dissociation of the Al-1 moiety. Therefore, the subsequent insertions will occur in a three-step process: 1) dissociation of co-catalyst 2) insertion of ethylene 3) recoordination of Al-1 to form the more stable bimetallic species. Thus far in this study, we have highlighted that the dissociation of Al-1 is preferable prior to the insertion of ethylene. 
Hence, the next comparison to be made was the potential effects that subsequent insertions induce and examine whether the length of the alkyl/polymeryl chain $\mathrm{R}$ on the $[\mathrm{rac}$ $\{\mathrm{EBTHI}\} \mathrm{Zr}-\mathrm{R}]^{+}$system affects either the incorporation of Al-1, the insertion of ethylene, or both. The computed coordination energies for the growing polymer chain generated via first, second and third ethylene insertions are summarized in Table 4.

\begin{tabular}{ccc}
\hline$[\text { rac- }\{\mathbf{E B T H I}\} \mathbf{Z r}-\mathbf{R}]^{+}$ & $\begin{array}{c}\text { Al-1 } \\
\mathbf{R e - c o o r d i n a t i o n} \\
\left(\mathbf{k c a l} \cdot \mathbf{m o l}^{-1}\right)\end{array}$ & $\begin{array}{c}\text { Ethylene } \\
\text { coordination } \\
\left(\mathbf{k c a l} \cdot \mathbf{m o l}^{-1} \mathbf{)}\right.\end{array}$ \\
\hline $\mathbf{1}^{\text {st }}$ Insertion $(\mathbf{R}=$ methyl) & -4.8 & -2.4 \\
$\mathbf{2}^{\text {nd }}$ Insertion $(\mathbf{R}=\boldsymbol{n}$-propyl) & -5.0 & -2.6 \\
$\mathbf{3}^{\text {rd }}$ Insertion $(\mathbf{R}=\boldsymbol{n}$-pentyl) & -3.0 & -1.0 \\
\hline
\end{tabular}

Table 4. A comparison between the respective coordination/re-coordination energies of the co-catalyst and monomer species.

The presence of Al-1 provides a stabilizing interaction with $[\mathrm{rac}-\{\mathrm{EBTHI}\} \mathrm{Zr}-\mathrm{R}]^{+}$throughout each insertion step. Generally, the extent to which the co-catalyst stabilizes the bimetallic species seems to decrease as the $\mathrm{Zr}-\mathrm{R}$ chain length increases. In contrast, ethylene coordination provides little, if any, stabilizing effects and thus a competition between the alkenyl moiety of the co-catalyst and monomer becomes more prevalent as the polymer chain grows.

Since Al-1 possesses two alkenyl chains with a terminal vinyl group that may compete with the ethylene coordination, once the co-catalyst has dissociated, the coordination and subsequent insertions of the vinyl group from oct-7-en-1-yl was investigated (Scheme 8). 
1.

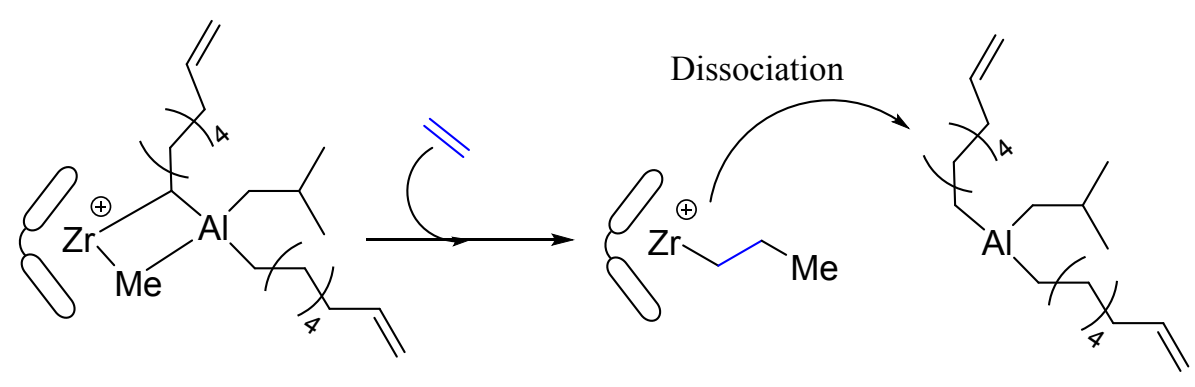

2.

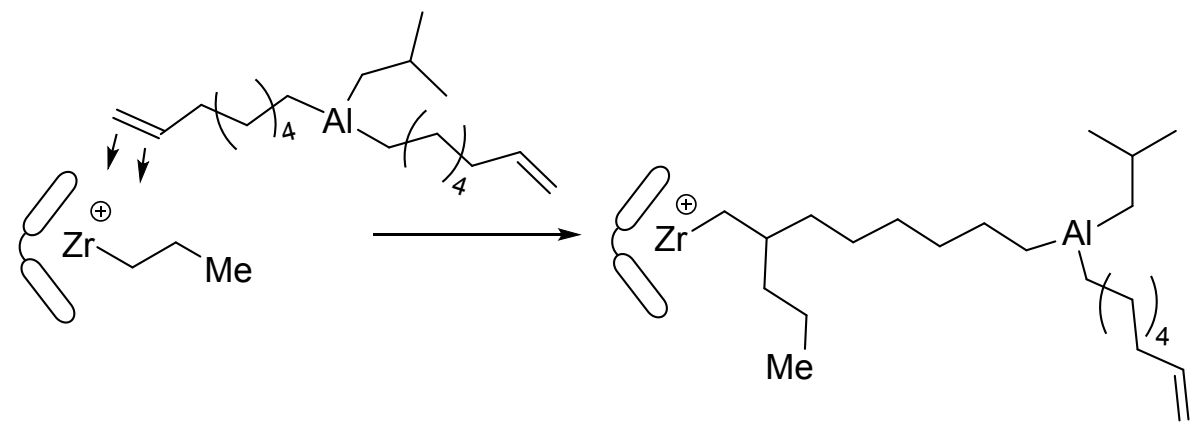

Scheme 8. The two-step mechanism for the re-coordination and insertion of a vinyl group from the Al-1 cocatalyst.

In order to highlight the competition present within this model, a comparison was made between the adducts formed from the active $[\mathrm{rac}-\{\mathrm{EBTHI}\} \mathrm{Zr}-\mathrm{R}]^{+}$catalyst and ethylene, and those leading to the vinyl group 1,2-insertions. For the sake of clarity, the following profile (Scheme 9) demonstrates the effects when a competitive environment is most significant: the third insertion of ethylene $v$ s. a vinyl 1,2-coordination/insertion to the $[\mathrm{rac}-\{\mathrm{EBTHI}\} \mathrm{Zr}-(n-$ pentyl) $]^{+}$system. 
Scheme 9. A comparison between the coordination/insertion of ethylene vs. a vinyl group coordination/insertion at the third insertion step. Note the initial difference in adduct stability.

The adducts produced by either monomer or co-catalyst coordination differ greatly, whereby the initial interaction of ethylene is destabilizing $\left(+4.0 \mathrm{kcal} \cdot \mathrm{mol}^{-1}\right)$ and the vinyl group coordination could arguably be in an equilibrium with the bimetallic resting state. Nevertheless, the vinyl coordination is much more stabilizing, and therefore favored, in comparison to the ethylene monomer. This concept is also in agreement with the weak coordination/dissociation proposal of the Al-1 co-catalyst. Kinetically, comparing the transition state barriers in Scheme 9, one observes that the vinyl 1,2-coordination/insertion pathway is in direct competition with the insertion of ethylene. The vinyl group 1,2-insertions generally become more viable as the chain length increases, referring to the competitive kinetics of the first, second and now third insertions of ethylene (Figures S12 and S13). 
Although the stabilities of the products differ, it is an interesting propensity that the vinyl coordination to the catalyst produces a more stable adduct, relative to the ethylene coordination/insertions. Therefore, our model suggests a growing competition that kinetically favors the formation of a branched product over a linear polymer.

\section{CONCLUDING REMARKS}

The Al-alkenyl compound Al-1 has been synthesized and employed as a LCB-promoter in the polymerization of ethylene catalyzed by homogeneous $r a c-\{\mathrm{EBTHI}\} \mathrm{ZrCl}_{2} / \mathrm{MAO}$ or heterogeneous $\mathrm{MAO}$ on silica-supported-rac-\{EBTHI $\} \mathrm{ZrCl}_{2} / \mathrm{TIBAL}$ catalytic systems. The use of this Al-based co-reagent induces a marked change in the rheological behavior of the PEs, unambiguously consistent with LCB generation. While the nature of LCB could not be unambiguously corroborated by ${ }^{13} \mathrm{C}$ NMR spectroscopy, it probably constitutes a regular Cbranched LCB microstructure, and most likely arises from efficient tandem insertion and transmetallation processes between $\mathrm{Al}$ - and $\mathrm{Zr}-$ species. The intermediacy of $\mathrm{Al} / \mathrm{Zr}$ heterobimetallic species, resulting from reversible coordination of Al-1 to [rac$\{\mathrm{EBTHI}\} \mathrm{Zr}-\mathrm{R}]^{+}$, was established and for the first time scrutinized in details by DFT computations.

Though rheological studies were employed as the main analytical technique in this study, they were not aimed at quantifying the amount of LCBs. Given the fact that, to reach such a quantitative analysis, a wider range of frequencies should be collected, only a trend for a very restricted range of samples was examined with a wish to understand the role of $\mathbf{A l - 1}$ co-catalyst as an efficient promoter of LCBs.

Because the $r a c-\{\mathrm{EBTHI}\} \mathrm{ZCl}_{2} / \mathrm{MAO}$ system has the intrinsic capability to generate LCB (minimal but noticeable amounts), forthcoming investigations shall be directed toward the evaluation of Al-1, as a co-catalyst and promoter of LCBs, in the presence of a catalyst 
system that, by itself, does not auto-generate LCB. Hence, experimental and computational studies on the analogous $\{n-\mathrm{BuCp}\}_{2} \mathrm{ZrCl}_{2} /$ metal-alkenyl systems are currently under way in our research groups to provide a complete rationale of the different reactivity of such Malkenyl co-reagents; the results of these investigations will be published in due course.

\title{
ASSOCIATED CONTENT
}

Supporting information is available free of charge on the ACS Publications website at DOI: synthetic procedures, NMR and rheological analyses of polymers.

\begin{abstract}
AKNOWLEDGMENTS
This work was gratefully supported by Total SA and Total Research and Technology Feluy (postdoctoral fellowships to OS, LP and KMG).
\end{abstract}

\section{REFERENCES AND NOTES}

1 Resconi, L.; Cavallo, L.; Fait, A.; Piemontesi, F. Selectivity in propene polymerization with metallocene catalysts. Chem. Rev. 2000, 100, 1253-1346.

2 Lai, S.-Y.; Wilson, J. R.; Knight, G, W.; Stevens, J. C.; Chum, P.-W. Elastic substantially linear olefin polymers. U.S. Pat. 5,272,236, 1993 (to Dow Chemical Co.).

3 Brant, P.; Canich, J. A. M.; Dias, A. J.; Bamberger, R. L.; Licciardi, G. G.; Henrichs, P. M. Long chain branched polymers and a process to make long chain branched polymers. WO Pat. 94/07930, 1994 (to ExxonMobil Chemical co.).

4 Kim, Y. S.; Chung, C. I.; Lai, S. Y.; Hyum, K. S. Melt rheological and thermodynamic properties of polyethylene homopolymers and poly(ethylene/ $\alpha$-olefin) copolymers with respect to molecular composition and structure. J. Appl. Polym. Sci. 1996, 59, 125-137. 
5 Rätzsch, M. Reaction mechanism to long-chain branched polypropylene. J. Macromol. Sci. A. 1999, 36, 1759-1769.

6 Ardakani, F.; Jahani, Y.; Morshedian, J. Effect of electron beam irradiation dose on the rheology, morphology, and thermal properties of branched polypropylene/polybutene-1 blend. Polym Eng Sci, 2014, 54: 1747-1756.

7 Parent, J. S.; Bodsworth, A.; Sengupta, S. S.; Kontopoulou, M.; Chaudhary, B. I.; Poche, D.; Cousteaux, S. Structure-rheology relationships of long-chain branched polypropylene: Comparative analysis of acrylic and allylic coagent chemistry. Polymer 2009, 50, 85-94.

$8 \quad$ Wang, X. C.; Tzoganakis, C.; Rempel, G. L. Chemical modification of polypropylene with peroxide/pentaerythritol triacrylate by reactive extrusion. J. Appl. Polym. Sci. 1996, $61,1395-1404$

9 Tian, J. H.; Yu, W.; Zou, C. X. The preparation and rheology characterization of long chain branching polypropylene. Polymer 2006, 47, 7962-7969.

10 Stanic, S.; Gottlieb, G.; Koch, T.; Göpperl, L.; Schmid, K.; Knaus, S.; Archodoulaki, V.M. Influence of Different Types of Peroxides on the Long-Chain Branching of PP via Reactive Extrusion. Polymers 2020, 12, 886-904.

11 Lu, B.; Chung, T. C. Synthesis of long chain branched polypropylene with relatively well-defined molecular structure. Macromolecules 1999, 32, 8678-8680.

12 Chum, P. S.; Kupper, W. J.; Guest, M. J. Materials properties derived from INSITE metallocene catalysts. Adv. Mater. 2000, 12, 1759-1767.

13 Weng, W; Markel, E. J.; Dekmezian, A. H. Synthesis of long-chain branched propylene polymers via macromonomer incorporation. Macromol. Rapid. Commun. 2001, 22, $1488-1492$. 
14 Kokko, E.; Pietikäinem, P.; Koivunen, J.; Seppälä, J. V. Long-chain-branched polyethene by the copolymerization of ethene and non-conjugated $\alpha, \omega$-dienes. J. Polym. Sci. 2001, $39,3805-3817$.

15 Pietikäinem, P.; Väänänen, R.; Seppälä, J. V. Copolymerization of ethylene and nonconjugated dienes with $\mathrm{Cp}_{2} \mathrm{ZrCl}_{2} / \mathrm{MAO}$ catalyst system. Eur. Polym. J. 1999, 35, 10471055.

16 Pietikäinem, R.; Seppälä, J. V.; Ahjopalo, L.; Pietilä, L.-O. Copolymerization of ethylene and non-conjugated dienes with $\mathrm{Cp}_{2} \mathrm{ZrCl}_{2} / \mathrm{MAO}$ catalyst system: effect of polymerization temperature on the copolymer structure. Eur. Polym. J. 2000, 36, 183-192.

17 Naga, N.; Imanishi, Y. Copolymerization of ethylene and 1,7-octadiene, 1,9-decadiene with zirconocene catalysts. Macromol. Chem. Phys. 2002, 203, 2155-2162.

18 Williamson, A.; Fink, G Alternating copolymers of ethylene and diolefins containing pendent functional groups. Macromol. Chem. Phys. 2003, 204, 1178-1190.

19 Das, C; Elguweri, M; Jiang, P.; Kang, S.; Kelchtermans, M.; McLeish, T.C.B.; Parkinson, M.; Read, D.J.; Redlich, M.P.; P. Shirodkar, P.P.; Soulages, J.M. Controlled Synthesis, Characterization, and Flow Properties of Ethylene-Diene Copolymers. Macromol. React. Eng. 2019, 13, 1800071-1800085.

20 Liu, P.; Liu, W.; Wang, W-J; Li, B-G.; Zhu, S. A Comprehensive Review on Controlled Synthesis of Long-Chain Branched Polyolefins: Part 3, Characterization of Long-Chain Branched Polymers. Macromol. React. Eng. 2017, 11, 1600012-1600032.

21 Wang, B.; Zhang, Y.-M.; Ma, Z.; Pan, L.; Yu, S-J; Li, Y.-S. Copolymerization of propylene with Si-containing $\alpha, \omega$-diolefins: how steric hindrance of diolefins affects long chain branch formation. Polym. Chem., 2016, 7, 2938-2946.

22 Uzawa, T.; Goto, K.; Uozumi, T.; Sugano, T.; Zhu, W.; Chung, T.C.M. Direct Synthesis of High-Melt-Strength Polypropylene Using the Fourth Generation Heterogeneous 
Ziegler-Natta Catalyst and Commercial Production Process. ACS Appl. Polym. Mater. 2020, 2, 1827-1838.

23 Liu, Y.; Qin, Y.; Dong, J-Y. Assessing 1,9-Decadiene/Propylene Copolymerization with Ziegler-Natta Catalysts to Long-Chain-Branched Polypropylene. Ind. Eng. Chem. Res. 2020, 59, 12038-12047.

24 Shroff, R. N.; Mavridis, H. Assessment of NMR and Rheology for the Characterization of LCB in Essentially Linear Polyethylenes. Macromolecules 2001, 34, 7362-7367.

25 Stadler, F. J.; Piel, C.; Klimke, J.; Parkinson, M.; Wilhem, M.; Kaminsky, W.; Munstedt, H. Influence of type and content of various comonomers on long-chain branching of ethene/ $\alpha$-olefin copolymers. Macromolecules 2006, 39, 1474-1482.

26 Stadler, F. J. Detecting very low levels of long-chain branching in metallocene-catalyzed polyethylenes, Rheol. Acta 2012, 51, 821-840.

27 Takeh, A.; Worch, J.; Shanbhag, S. Analytical rheology of metallocene-catalyzed polyethylenes, Macromolecules 2011, 44, 3656-3665.

28 Stadler, F. J.; Karimkhani, V. Correlations between the Characteristic Rheological Quantities and Molecular Structure of Long-Chain Branched Metallocene Catalyzed Polyethylenes, Macromolecules 2011, 44, 13, 5401-5413.

29 Holtcamp, M. W.; Day, G. S.; Hagadorn, J. R.; Palafow, O. J.; Mathiamagan, R.; Canich, J. M. Aluminum alkyls with pendant olefins for polyolefin reactions, WO Pat. Appl. 2017039995 A1 (to ExxonMobil co.).

30 Lee, H. J.; Baek, J. W.; Kim, T. J.; Park, H. S.; Moon, S. H.; Park, K. L.; Bae, S. M.; Park, J.; Lee, B. Y. Synthesis of Long-Chain Branched Polyolefins by Coordinative Chain Transfer Polymerization, Macromolecules 2019, 52, 9311-9320.

31 Hsieh, T; Randall, J. C. Ethylene-1-Butene Copolymers. 1. Comonomer Sequence Distribution, Macromolecules 1982, 15, 353-360. 
32 Trinkle, S.; Friedrich, C. Van Gurp-Palmen-plot: a way to characterize polydispersity of linear polymers, Rheol. Acta 2001, 40, 322-328.

33 Trinkle, S.; Walter, P.; Friedrich, C. Van Gurp-Palmen Plot II - classification of long chain branched polymers by their topology Rheol. Acta 2002, 41, 103-113.

34 Malmberg, A.; Kokko, E.; Lehmus, P.; Löfgren, B.; Seppälä, J.V. Long-Chain Branched Polyethene Polymerized by Metallocene Catalysts $\mathrm{Et}[\mathrm{Ind}]_{2} \mathrm{ZrCl}_{2} / \mathrm{MAO}$ and Et [IndH $]_{2} \mathrm{ZrCl}_{2} / \mathrm{MAO}$, Macromolecules 1998, 31, 8448-8454.

35 Stadler, F. J.; Munstedt, H. Correlation between the shape of viscosity functions and the molecular structure of long-chain branched polyethylenes, Macromol. Mater. Eng. 2009, $294,25-34$.

36 Stadler, F. J.; Chen, S.; Chen, S. On "modulus shift" and thermorheological complexity in polyolefins, Rheol. Acta 2015, 54, 695-704.

37 Yan, Z-C.; Stadler, F. J. Classification of thermorheolegical complexity for linear and branched polyolefins, Rheol. Acta 2018, 57, 377-388.

38 The $\operatorname{dlog}\left|\eta^{*}\right| / \operatorname{dlog} \omega$ vs. $\delta$ plots for several samples, namely PE8, PE10, PE11, PE14, showed a certain deviation from linear relation (Figure S6). This may stem from some machine errors at low torque, although the raw data was manually checked and no anomalies were detected. Another explanation is that the true Newtonian viscosity value, which we could get from the approach proposed, is apparently underestimated; see: Stadler, F. J.; Munstedt, H. Numerical description of shear viscosity functions of longchain branched metallocene-catalyzed polyethylenes, J. Non-Newtonian Fluid Mech. 2008, 151, 129-135.

39 Yang, Q.; Jensen, M. D.; McDaniel, M. P. Alternative View of Long Chain Branch Formation by Metallocene Catalysts, Macromolecules 2010, 43, 8836-8852. 
40 It can be noted that the quality of the rheological data reported in Fig. 3 and 4 is remarkably different. The analyses have been performed in two different laboratories, albeit with the same type of Rheometer and under the same operative conditions. This may be the origin of the difference observed.

41 The $\operatorname{dlog}\left|\eta^{*}\right| / \operatorname{dlog} \omega v$ s. $\delta$ plots for samples PE15-PE22 appeared to be generally linear (Figure S7). 